\title{
Perception Analysis of Microsoft Windows OS Users
}

\author{
Manik Mahachandra*, Heru Prastawa, Novie Susanto, and Dhialma Yonathan Susilo \\ Departement of Industrial Engineering, Faculty of Engineering, Diponegoro University, Semarang - Indonesia
}

\begin{abstract}
Nowadays, almost every individual in working situation using a Personal Computer (PC), whether desktop or laptop. The most common operating system (OS) used until now is Microsoft Windows. However, some people felt anxious in using the few most updated version of Windows. This emotion was strongly related with the experience in in using the product. Therefore, this study was conducted to measure the cognitive factors (usability and satisfaction) via System Usability Scale (SUS) and the affective factors (emotions) through Geneva Emotion Wheel (GEW) method. Involving 400 participants, data were collected through online questionnaire. The results showed that the best usability operating system was Windows 7 (SUS score $=69.20$ or Good), the best operating system that bring positive emotions to the users was Windows 10 (GEW score $=3.42$ ). These results could be applied in choosing and designing a better working system with Microsoft Windows as the computer operating system in the future.
\end{abstract}

Keywords: Affective; Cognitive; Geneva Emotion Wheel; Operating System; System Usability Scale.

\section{Introduction}

In this era, a product ought to exceed the consumers' expectations [1]. Competition between products extends from competing only on the utility factor, penetrating into factors that can provide emotional satisfaction. According to [2], pleasure in a product comes from the relationship between a person and the product. There are three types of fun in a product that is the emotional, hedonic, and practical benefits associated with the product. Pleasure is one of the emotional dimensions [3].

In the early 1970s, necessity was no longer the primary reason consumers bought goods [4]. Compared with durability, someone prefers something beautiful, trendy, user friendly, secure, and environmentally friendly. Consumers choose the product not just because of its function, but also the social and emotional aspects. According to [5], the social and emotional value includes sensory enjoyment, attainment of desired mood states, the achievement of social goals, and the concept of self fulfillment. Emotional attributes can make consumers willing to interact and encourage decisions to use the product on a long-term or continuous basis. Thus, the consumer's emotional response affects the stimulation and emotional satisfaction or perception of a product [6].

In this increasingly sophisticated era of globalization, individuals are required to complete their work using Personal Computer (PC). Inside each PC, there is an operating system (OS), as a resource manager that provides a set of services to the user. Examples of operating systems are Unix, Linux, Disk Operating System (DOS), Microsoft Windows, and Macintosh Operating System (Mac OS). The purpose of the operating system is to make the computer easier and more comfortable to use, allows the computer system resources to be used in an efficient way, and enable effective development, testing, and implementation of the functions of the new system without disrupting existing services.

Based on the Netmarketshare website in February 2017, the most widely used operating system is the Microsoft Windows OS. On that time, there were 39\% users of Windows 7, 2\% users of Windows $8,12 \%$ users of Windows 8.1, and 47\% users of Windows 10 . According to Microsoft website, the minimum specifications for Windows 7, 8, and 10 are similar, although for Windows 10 requires at least $800 \times 600$ display screen resolution. The minimum specifications are $1 \mathrm{GHz}$ processor, $1 \mathrm{~GB}$ (32-bit) or $2 \mathrm{~GB}$ (64-bit) RAM, 16 GB (32-bit) or 20 GB (64-bit) hard disk space OS, and DirectX 9 Graphics card. In terms of excellent features, Windows 10 has Cortana, the latest search functionality. For browsers, Windows 10 has Microsoft Edge while Windows 7 and 8 use Internet Explorer. For the interface layout, Windows 10 returns Start Menu button as in Windows 7, while Windows 8 Start Menu button is hidden.

According to [7], the design of a product has three objectives, i.e. desirable, usable, and useful. Desirable term means aesthetically appealing design. Usable shows that the design is easy to understand, learn, and use. Whilst in useful term, the design is managed in accordance with the original purpose of the draft. Based on these factors, a preliminary study of Windows 7, 8 and 10 OS users in Semarang was carried out. Using an online questionnaire, 76 participants were involved in this preliminary study. Among them, $47 \%$ were male, $80 \%$ were 20-24 years old, and 76\% were students. About 36\%

Corresponding author: manik.mahachandra@ft.undip.ac.id 
of them used Windows 7 on their PC, while 26\% used Windows 8, and the rest applied Windows 10.

Table 1. Preliminary study mapping.

\begin{tabular}{|c|l|c|c|c|}
\hline No & \multicolumn{1}{|c|}{ Category } & OS 7 & OS 8 & OS 10 \\
\hline 1 & Usefulness & $92.6 \%$ & $90 \%$ & $96.5 \%$ \\
\hline 2 & Usable & $96.3 \%$ & $95 \%$ & $100 \%$ \\
\hline \multirow{2}{*}{3} & Satisfaction of the features & $55.6 \%$ & $75 \%$ & $34.4 \%$ \\
\cline { 2 - 5 } & $\begin{array}{l}\text { Interested on the } \\
\text { color/layout design }\end{array}$ & $18.5 \%$ & $25 \%$ & $58.6 \%$ \\
\cline { 2 - 5 } & Anxious of error & $25.9 \%$ & $35 \%$ & $10.3 \%$ \\
\hline
\end{tabular}

Moreover, about $66.7 \%$ participants chosen Windows 7 as the OS because it was easy to use, lighter, compatible with may software, simple, and not complicated. About $85 \%$ of the Windows 8 users claimed that this OS had a boot time faster than previous version, had unique features and design, and also better in user security and website protection features. Whilst, 96.6\% participants who were familiar with Windows 10 stated that this OS more interesting, more comfortable to use, and had the newest searching feature.

Based on the preliminary study, we knew that computer users demand a useful OS in high degree of usability. However, some users experienced anxiety while using one of the OS. Therefore, this study aims to analyze further the perspective aspects of the three OS, which can be measured through affective and cognitive measurement. Later, the affective and cognitive point of views resulted in this study can be considered in building a better information system interface to be apllied in the Low-Carbon Society to support the sustainable living.

Affective and cognitive aspects, according to Peter \& Olson (2005), is a mental response of consumers arising from stimuli that arise in their environment (Tjiptodjojo, 2012). Affection relates more to feelings, while the cognitive associates more to the mind. These stimuli will form a perception that will affect the consumer's physical actions that can be measured and observed directly or the so-called behavior. According to ISO / DIS 9241-11.2 regulation, usability of product can help specified users to achieve its goals more effectively, efficiently and satisfactorily within its product's scope. Thus, cognitive factors can be measured using usability measurement tools. Affective factors, moreover, can be quantified via users' emotional reactions to an object, event, or situation.

According to Santosa (1997), the negative attitude of users while using a computer can affect the user's performance and reduce his ability to learn computer systems. User anxiety can have an effect on the slow process of user learning.

The cognitive process can be considered analogous to the computer. In computer system, information input is processed in various ways, including selection, comparison, combination with other information already in memory, alteration in shape, rearrangement, etc.
According to [8], the cognitive domain consists of six aspects, i.e. knowledge (the ability to recognize or recall something objects, ideas, procedures, principles or theories ever discovered based on experience), understanding, application, analysis an integrity into elements or parts so clearly defined), synthesis (the ability to integrate separate parts into an integrated whole), and assessment or evaluation (the ability to make decisions, express opinions or judge according to several criteria certain both qualitative and quantitative) [8].

Affect is someone's affective responses, the mental feeling experienced by a person against a stimulus or event. [9] distinguishes the type of affective response into four elements, i.e. emotions, moods, sentiments, and evaluations (emotional/personality trait). Emotions describe the tendency of humans to act are simply formulated as the activation of the sympathetic, fight or flight. This formulation then puts the emotions in the opposite poles of positivity and negative poles, comfort and discomfort, caused by the evaluation made by the mind against external stimuli or imaginative stimuli. Emotion is a feeling experienced by a person when facing a particular situation [10].

\section{Method}

\subsection{Geneva Emotion Wheel}

Geneva Emotion Wheel (GEW) is an emotional measurement tool that has been tested both theoretically and empirically to measure the emotional reaction to an object, event or situation [11]. The GEW diagram consists of emotions based on the type of emotion that is positive emotions and negative emotions (right and left), as well as control types, from high to low (upper and lower) control types. This diagram thus separating emotion in four quadrants, i.e. negative emotions-low control, negative emotions-height control, positive emotions-low control, and positive emotions-height control. Each quadrant contains five types of emotions based on the quadrant type, which is formed based on Russel's emotional theory. Table 2 shows the affective variables involved in this study.

\subsection{System Usability Scale}

System Usability Scale (SUS) is a simple subjective usability measure with 10 statement items, developed by John Brooke in 1986 [12]. SUS applies the Likert scale, with minimum threshold of zero and maximum threshold of 100. Table 3 and Figure 1 shows the SUS employed in this study.

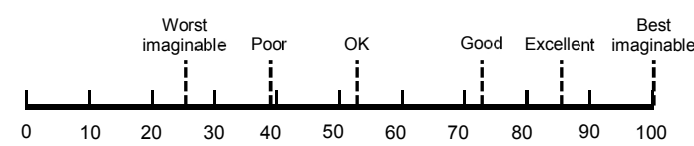

Fig. 1. System Usability Scale (SUS). 
Table 2. Affective variables measured using GEW.

\begin{tabular}{|c|c|c|}
\hline & Positive Valence & Negative Valence \\
\hline \multirow{5}{*}{$\begin{array}{c}\text { High } \\
\text { Control }\end{array}$} & Interesting & Irritated \\
\hline & Entertaining & Make want to sneer \\
\hline & Make proud & Disgusting \\
\hline & Giving pleasure & Regret \\
\hline & Enjoy & Disappointed \\
\hline \multirow[t]{5}{*}{$\begin{array}{c}\text { Low } \\
\text { Control }\end{array}$} & Feel easy & $\begin{array}{l}\text { There is a feeling of } \\
\text { guilt when operating }\end{array}$ \\
\hline & Awe & Embarrassed \\
\hline & Helpful & $\begin{array}{l}\text { Fear of not } \\
\text { understanding }\end{array}$ \\
\hline & Fascinate & Makes no spirits \\
\hline & Feel like to use again & Sadden \\
\hline
\end{tabular}

Table 3. Cognitive variables measured using SUS.

\begin{tabular}{|c|c|}
\hline No & Statement \\
\hline 1 & $\begin{array}{l}\text { I think to be happy to use this product as often as } \\
\text { possible. }\end{array}$ \\
\hline 2 & I found that this product should not be complex. \\
\hline 3 & I think this product is easy to use. \\
\hline 4 & $\begin{array}{l}\text { I think I need someone to guide me to be able to use } \\
\text { this product. }\end{array}$ \\
\hline 5 & $\begin{array}{l}\text { I found several functions in this product that are well } \\
\text { integrated and complementary. }\end{array}$ \\
\hline 6 & $\begin{array}{l}\text { I think there are too many inconsistencies in this } \\
\text { product. }\end{array}$ \\
\hline 7 & $\begin{array}{l}\text { I imagine most people will learn to use this product } \\
\text { very quickly. }\end{array}$ \\
\hline 8 & I found this product very impractical / difficult to use. \\
\hline 9 & I feel very confident using this product. \\
\hline 10 & $\begin{array}{l}\text { I need to learn a lot before I'm ready to use this } \\
\text { product. }\end{array}$ \\
\hline
\end{tabular}

\subsection{Data Collection}

Four hundred people above 15 years old joined in the data collection process as participants. They were asked about the OS they use. The System Usability Scale and Geneva Emotion Wheel were asked separatedly. Questionnaire was spread online, together with a short video about the use of search feature on every OS.

\section{Results and Discussion}

\subsection{The Cognitive Factors}

System Usability Scale calculation was derived from the amount of score contribution from each statement item. The value of each item ranged from 0 to 4 . For items 1, 3, 5,7 , and 9 , the score value was a scale position minus 1 . For items 2, 4, 6, 8, and 10, the score score was 5 minus scale position. To get the overall value was the total score multiplied by 2.5 . The odd number statement in the SUS method was a positive statement, while the even number statement was a negative statement. Table 4 shows the the average scores of SUS.

Table 4. Average SUS scores.

\begin{tabular}{|c|c|c|}
\hline Statements & $\begin{array}{l}\text { Operating } \\
\text { System }\end{array}$ & $\begin{array}{l}\text { Average } \\
\text { SUS } \\
\text { Score }\end{array}$ \\
\hline \multirow{3}{*}{$\begin{array}{l}\text { I think to be happy to use } \\
\text { this product as often as } \\
\text { possible. }\end{array}$} & Windows $7 *$ & 2.71 \\
\hline & Windows 8 & 2.20 \\
\hline & Windows 10 & 2.69 \\
\hline \multirow{3}{*}{$\begin{array}{l}\text { I found that this product } \\
\text { should not be complex. }\end{array}$} & Windows $7 *$ & 1.78 \\
\hline & Windows 8 & 1.56 \\
\hline & Windows 10 & 1.60 \\
\hline \multirow{3}{*}{$\begin{array}{l}\text { I think this product is easy } \\
\text { to use. }\end{array}$} & Windows $7 *$ & 3.39 \\
\hline & Windows 8 & 2.37 \\
\hline & Windows 10 & 2.66 \\
\hline \multirow{3}{*}{$\begin{array}{l}\text { I think I need someone to } \\
\text { guide me to be able to use } \\
\text { this product. }\end{array}$} & Windows $7 *$ & 3.01 \\
\hline & Windows 8 & 2.19 \\
\hline & Windows 10 & 2.15 \\
\hline \multirow{3}{*}{$\begin{array}{l}\text { I found several functions in } \\
\text { this product that are well } \\
\text { integrated and } \\
\text { complementary. }\end{array}$} & Windows 7 & 2.52 \\
\hline & Windows 8 & 2.46 \\
\hline & Windows $10^{*}$ & 2.79 \\
\hline
\end{tabular}


Table 4. Average SUS scores (continued).

\begin{tabular}{|c|c|c|}
\hline Statements & $\begin{array}{c}\text { Operating } \\
\text { System }\end{array}$ & $\begin{array}{l}\text { Average } \\
\text { SUS Score }\end{array}$ \\
\hline \multirow{3}{*}{$\begin{array}{l}\text { I think there are too many } \\
\text { inconsistencies in this } \\
\text { product. }\end{array}$} & Windows $7 *$ & 2.45 \\
\hline & Windows 8 & 1.98 \\
\hline & Windows 10 & 2.26 \\
\hline \multirow{3}{*}{$\begin{array}{l}\text { I imagine most people will } \\
\text { learn to use this product } \\
\text { very quickly. }\end{array}$} & Windows $7 *$ & 3.14 \\
\hline & Windows 8 & 2.27 \\
\hline & Windows 10 & 2.48 \\
\hline \multirow{3}{*}{$\begin{array}{l}\text { I found this product very } \\
\text { impractical / difficult to use. }\end{array}$} & Windows $7^{*}$ & 2.92 \\
\hline & Windows 8 & 2.04 \\
\hline & Windows 10 & 2.35 \\
\hline \multirow{3}{*}{$\begin{array}{l}\text { I feel very confident using } \\
\text { this product. }\end{array}$} & Windows $7^{*}$ & 3.03 \\
\hline & Windows 8 & 2.41 \\
\hline & Windows 10 & 2.71 \\
\hline \multirow{3}{*}{$\begin{array}{l}\text { I need to learn a lot before } \\
\text { I'm ready to use this } \\
\text { product. }\end{array}$} & Windows $7 *$ & 2.75 \\
\hline & Windows 8 & 1.97 \\
\hline & Windows 10 & 1.93 \\
\hline
\end{tabular}

* The highest score among others.

Based on the Table 4, Windows 7 got highest score on 9 out of 10 statements in SUS. This condition showed that participants were satisfied with most of the feature of this OS. However, participants found that several functions in Windows 10 was more integrated and complete than the others. To summarize, Figure 2 shows the final results of SUS. Based on this graph, the Windows 7 was claimed as the best OS in usability (SUS $=69.20 /$ Good), compared to Windows 8 (SUS $=53.57 / \mathrm{OK}$ ) and Windows 10 (SUS $=59.03 / \mathrm{OK})$. This finding was inline with [13] research results.

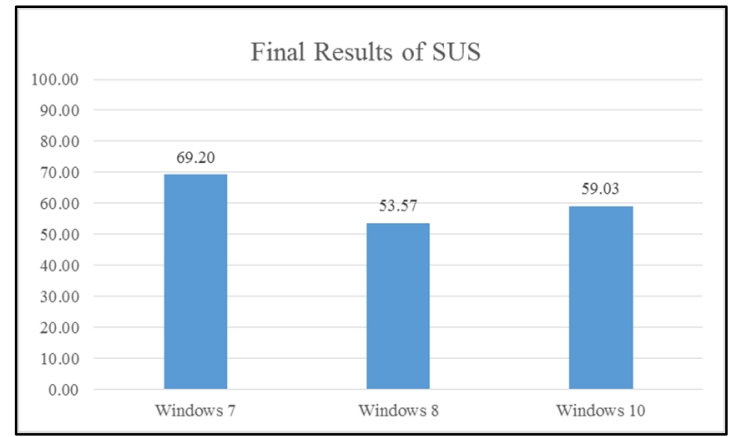

Fig. 2. System Usability Scale (SUS).

\subsection{The Affective Factors}

Using the GEW method, there were 20 emotional forms perceived by the participants, where 10 emotions were positive and the rest were negative. User emotional judgments were represented and translated in scale from 0 (not feel the same) to 5 (greatly sense the emotion). To get the final score of each emotion, calculation of the average score of each emotion, from positive category and negative category, were carried out. Figure 3 shows the emotions value comparison from each operating system.

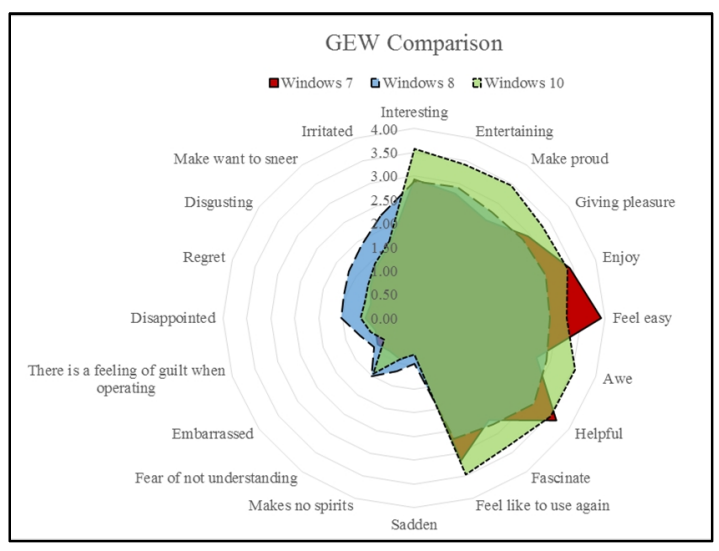

Fig. 3. System Usability Scale (SUS).

The spider chart in Figure 3 gives illustration that Windows 10 brought more positive emotions than others. Participants claimed that this newest OS was interesting to use (3.58), entertaining (3.42), made proud (3.46), gave pleasure (3.31), awesome (3.55), and fascinated (3.35). Moreover, they felt like to use this OS again (3.47). Surprisingly, Windows 8 , not only low in positive emotions, but also gave negative emotions to the participants. They claimed to have irritated feeling (2.28), wanted to sneer (1.89), disgusting (1.69), regret (1.55), disappointment (1.53), felt guilty (1.20), embarrassed (1.05), fear of not understand the system (1.52), had no spirit (1.18), and sad (0.97). Furthermore, Windows 7 brought highest positive emotions than others in feel easy (3.91), enjoy (3.42), and feel helpful (3.68).

\subsection{The Overall Usability Factors}

Finally, the final scores of SUS and GEW were analyzed to identify the OS that have high usability than others. The scores are shown in Table 5.

Table 5. Final score of SUS and GEW.

\begin{tabular}{|c|c|c|c|}
\hline \multirow{2}{*}{$\begin{array}{c}\text { Operating } \\
\text { System }\end{array}$} & SUS & \multicolumn{2}{|c|}{ GEW Score } \\
\cline { 3 - 4 } & Score & Positive Emotion & Negative Emotion \\
\hline Windows 7 & $69.20^{\mathrm{a}}$ & 3.07 & $1.04^{\mathrm{a}}$ \\
\hline Windows 8 & $53.57^{\mathrm{b}}$ & $2.86^{\mathrm{b}}$ & $1.48^{\mathrm{b}}$ \\
\hline Windows 10 & 59.03 & $3.42^{\mathrm{a}}$ & 1.14 \\
\hline
\end{tabular}


a The best; $\mathrm{b}$ The worst.

Using the GEW method, there were 20 emotional forms perceived by the participants, where 10 emotions were positive and the rest were negative. User emotional judgments were represented and translated in scale from 0 (not feel the same) to 5 (greatly sense the emotion). To get the final score of each emotion, calculation of the average score of each emotion, from positive category and negative category, were carried out [10]. Figure 3 shows the emotions value comparison from each operating system.

Based on the data above, it can be concluded that through the SUS method, it is found that users want an operating system that is not complex, easy, understandable, integrated and complementary operating system well, system consistency, can be learned quickly, and practically used. Through the GEW method, when users use the operating system it is found that the user wants a feeling of being easy, feeling helpful, amazed, interesting, proud, admirable, feeling like to use again, enjoy, entertain, and give pleasure. In addition, users do not want feelings of annoyance, make want to sneer, make sick, sorry, make fear do not understand, and disappointed. This results strenghten the theory in [1], [2], [3], [5], [7], and [9] in showing human needs and preference in choosing and buying products.

Differences in user perceptions of Microsoft Windows 7,8 , and 10 show that in the cognitive aspects of the SUS method, Windows 7 excels in the fun aspect to use as often as possible, products that are not complex or simpler, easier or easier to use, guidance for use, consistency when used, learning to use the product very quickly, very practical or not difficult to use, users are very confident to use, and do not need to learn much to be ready to use the product. As for aspects of functionality in integrated products and complement each other with the highest score obtained by Windows 10 . Moreover, it is known that Windows 10 showed the most positive emotions, whilst the most negative one was in Windows 7.

Based on the affective and cognitive factors, the words used in the extended operating system include not only grammatical structures and learning about the meaning of a word, but also the proper use of language so that it can be understood by the user. Moreover, a system that allows to teach users in tutorial settings and user-centered and engage as many users as possible so they can influence them to understand the system. Voice notifications might also be addedd when the user does not focus on the screen. Then, use of the right colors for design for users who are color blind or other visual disorders etc. The psychological and physiological relationship of shapes, materials, and colors must also be considered to achieve harmony of product appearance in the eyes of users. The designer must have the skills to apply the shapes and colors taking into account age, gender, ethnicity and cultural differences for the target product group to capture the user's mood; especially for trend-driven social groups such as pre-teens and young adolescents as well. Finally, the dynamic interaction design with users in a human-like frame through dialog boxes can also be added.

\section{References}

1. P. Kotler, K.L. Keller, Marketing Management, 14th Edition. (Pearson Prentice Hall Inc., New Jersey, 2012)

2. P.W. Jordan, Designing Pleasureable Products: An Introduction to the New Human Factors (CRC Press Book, New York, 2000)

3. R. Mauro, T. John, S. Kaori, The role of appraisal in human emotions: A cross-cultural study, Journal of Personality and Social Psychology, 62, 2, 301-317 (1992)

4. D. Gumulya, P. Nastasia, Kajian Teori Emotional Design, Jurnal Desain, 3, 1, 1-20 (2015)

5. J.N. Sheth, B. Mittal, B.I. Newman, Customer Behavior: Consumer Behavior and Beyond (The Dryden Press, Fort Worth, 1999)

6. Darsono, Faktor Emosi dalam Perilaku Konsumen, Dharma Ekonomi, XIX, 36 (2012)

7. M.S. Sanders, E. McCormick, Human Factors in Engineering and Design (McGraw-Hill, Singapore, 1992)

8. W. Huitt, Bloom et al.'s taxonomy of the cognitive domain, (Educational Psychology Interactive, Valdosta, Valdosta State University, GA, 2011)

9. P.M.A. Desmet, To love and not to love: Why do products elicitmixed emotion. Proceedings of the first international conference on Design \& Emotion, 6773 (1999)

10. L. Damien, B. Nathalie, Emotion and Interface Design: How to measure interface design emotional effect? (KEER 2014, Linko ping, 2014)

11. K.R. Scherer, V. Shuman, J.R.J. Fontaine, C. Soriano, The GRID meets the Wheel: Assessing emotional feeling via self-report, In J.R.J. Fontaine, K.R. Scherer, C. Soriano (Eds.), Components of emotional meaning: A sourcebook. (Oxford University Press, Oxford, 2013)

12. R.A. Grier, A. Bangor, P. Kortum, S.C. Peres, The system usability scale: Beyond standard usability testing, Proceeding of the Human Factors and Ergonomics Society Annual Meeting, 57, 1, 187-191 (2013)

13. N. Jansen, Usability Evaluation of Windows 8 with Keyboard and Mouse (Norwegian University of Science and Technology, Trondheim (2013) 